\title{
Concepções de pais e professores sobre a inclusão de crianças autistas*
}

\author{
Emellyne Lima de Medeiros Dias Lemos, Nádia Maria Ribeiro Salomão, ^ \\ Fabiola de Sousa Braz Aquino, Cibele Shirley Agripino-Ramos \\ Universidade Federal da Paraíba, João Pessoa, PB, Brasil
}

\begin{abstract}
Resumo
Este estudo objetivou analisar as concepções de pais e professores acerca da criança autista e do seu processo de inclusão escolar. Participaram seis professores de escolas regulares da cidade de João Pessoa-PB e oito pais de crianças diagnosticadas com Transtorno do Espectro Autista. Foram realizadas entrevistas, que foram gravadas e transcritas integralmente e os dados submetidos à Análise de Conteúdo. Os resultados indicaram que os pais demonstraram expectativas voltadas para a socialização e para aprendizagens acadêmicas, enquanto os professores mencionaram em suas estratégias a adoção de práticas mais voltadas à socialização. Destacou-se também que pais, à medida que acompanham o desenvolvimento de seus filhos, e professores, a partir do contato com crianças autistas, relataram ter expectativas mais positivas em relação a estas crianças. Conhecer as concepções de pais e professores é fundamental para promover a inclusão escolar de crianças autistas, que ocorre através da participação efetiva das duas partes.
\end{abstract}

Palavras-chave: inclusão; autismo; concepções.

\section{Parents and teachers conceptions about the inclusion of autistic children}

\begin{abstract}
The purpose of this study was to analyze parents and teachers conceptions with respect to autistic children and the process of school inclusion of these children. Six teachers of regular schools in the city of João Pessoa-PB and eight parents of children diagnosed with Autism Spectrum Disorder participated in this research. Interviews were recorded and transcribed and the data submitted to content analysis. The results indicated that parents demonstrated expectations towards the children socialization and academic learning while the strategies outlined by the teachers emphasized the adoption of practices more focused on socialization. It was also noted that parents, as they followed their children development, and teachers, as they had contact with autistic children, reported more positive expectations concerning these children. Knowing the concepts of parents and teachers as regards autistic children is essential to understand that the successful implementation of school inclusion may be achieved through the active participation of both parties.
\end{abstract}

Keywords: inclusion; autism; conceptions.

\section{Introdução}

O autismo foi descrito inicialmente pelo psiquiatra austríaco Leo Kanner, no ano de 1943, com base nos casos de 11 crianças que ele acompanhava e que apresentavam prejuízos em três aspectos: relações sociais, comunicação/ linguagem e comportamento. Kanner (1943) afirmou que indivíduos com autismo possuíam uma inabilidade inata para se relacionarem emocionalmente com as demais pessoas, o que dependeria de um aspecto biológico.

A partir dessa descrição inicial, surgiram outras explicações para o autismo. No período entre 1943 e 1963, o autismo é concebido como um transtorno emocional, sendo atribuída às mães e/ou aos pais pouco afetuosos a responsabilidade pela alteração dos seus filhos. Entre os anos de 1963 e 1983, foi rejeitada a hipótese de que o autismo derivava da relação pouco afetuosa dos pais com os seus filhos, surgindo explicações que consideravam a existência de uma alteração cognitiva para as dificuldades encontradas no autismo (RIVIÈRE, 2004). Foi sugerido, no começo desse período, que o autismo era um transtorno cerebral que estaria presente desde a infância (KLIN, 2006).

\footnotetext{
$\star$ Apoio Financeiro CNPq.

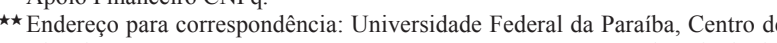
Ciências Humanas Letras e Artes - Campus I. Departamento de Psicologia. Cidade Universitária. João Pessoa, PB - Brasil. CEP: 58059-900. E-mail: emellyne@gmail.com,nnmrs@uol.com.br, fabiolabrazaquino@gmail.com, cibeleagripino@yahoo.com.br
}

A partir da década de 1980 , o autismo passou a ser considerado um Transtorno Global do Desenvolvimento (TGD) ou Transtorno Invasivo do Desenvolvimento (TID), visto que alterações estão presentes muito cedo na vida da criança (BOSA; CALLIAS, 2000). Em 2013, o Manual Diagnóstico e Estatístico dos Transtornos Mentais, da Associação Americana de Psiquiatria, em sua última edição (DSM-V), adota a expressão "Transtorno do Espectro Autista" (TEA), permitindo uma aproximação mais realista da heterogeneidade dos casos, principalmente em relação às habilidades verbais e ao nível linguístico e comportamental (AMERICAN PSYCHIATRIC ASSOCIATION [APA], 2013). Dentre as explicações para o autismo, tem-se destacado nos últimos anos duas perspectivas: a desenvolvimentista e a cognitivista.

A perspectiva desenvolvimentista toma o desenvolvimento típico como base para compreender o desenvolvimento da criança com autismo. Desse modo, tal perspectiva considera que há, nas crianças com autismo, um desvio no desenvolvimento, o que pode estar relacionado a problemas biológicos, que vem a acarretar um prejuízo na interação social, assim como no desenvolvimento da linguagem e no desenvolvimento do indivíduo como um todo (LAMPREIA, 2004; 2009).

A perspectiva cognitivista, por sua vez, defende que, no autismo, há uma incapacidade na compreensão do estado mental de outras pessoas (MITCHELL; 
O’KEEFE, 2008), condição que é atribuída a um prejuízo no mecanismo cognitivo inato (LAMPREIA, 2004). Assim, o autismo é explicado, dentro dessa perspectiva, em termos de uma teoria da mente, que diz respeito à capacidade de inferir sobre os estados mentais dos outros indivíduos e, a partir daí, predizer o comportamento deles (BOSA; CALLIAS, 2000). De acordo com esse pressuposto, o indivíduo com autismo não é capaz de se colocar sob o ponto de vista de outra pessoa, ou seja, não demonstra empatia (ASSUMPÇÃO JR. et al., 1999).

Os autores que adotam essa perspectiva afirmam que há, nos indivíduos com autismo, uma incapacidade para identificarem, compreenderem e atribuírem sentimentos e intenções a outros indivíduos. Dessa incapacidade de metarrepresentação, denominada por Baron-Cohen (2008) de "cegueira mental", decorreriam os déficits na linguagem e no relacionamento social (ASSUMPÇÃO JR.; PIMENTEL, 2000; TAMANAHA; PERISSINOTO; CHIARI, 2008).

Considera-se importante referir, ainda, que há explicações que apontam para a existência de componentes genéticos ou de fatores neurobiológicos presentes nesse transtorno, o que, no primeiro caso, tem sido indicado através de estudos envolvendo famílias com um ou mais membros autistas, assim como estudos de gêmeos. Estudos envolvendo gêmeos, por exemplo, demonstram que a concordância para o autismo em monozigóticos apresenta uma variação de 36 a 92\%, enquanto em gêmeos dizigóticos a concordância é baixa ou até mesmo nula (CARVALHEIRA; VERGANI; BRUNONI, 2004).

Quanto aos fatores neurobiológicos associados ao autismo, os progressos na área de imagem cerebral têm permitido demonstrar que indivíduos autistas podem apresentar alterações neurológicas, tais como tamanho do cérebro superior à média, mas tendo as redes de conexão entre as partes do cérebro geralmente menos desenvolvidas e disfunções em regiões cerebrais, como o cerebelo, os lobos temporais, a amígdala e o hipocampo (CARVALHEIRA et al., 2004; DUMAS, 2011).

Desde a primeira descrição feita por Kanner, em 1943, inúmeras pesquisas (BOYD et al., 2009; GUPTA; STATE, 2006; FERNANDES et al., 2008; HAPPÉ; RONALD; PLOMIN, 2006; MACHADO et al., 2003; SANINI; SIFUENTES; BOSA, 2013) sobre o autismo, nas mais diferentes áreas do conhecimento, foram realizadas, mas muitos aspectos permanecem inconcludentes, sobretudo em relação à etiologia, ao prognóstico e às possibilidades terapêuticas.

O autismo é considerado uma síndrome complexa que envolve desvios no desenvolvimento desde os primeiros anos de vida nas áreas de interação social, comunicação e comportamento, com múltiplas causas e manifestações que contemplam ampla variabilidade de sintomas e de respostas às intervenções (APA, 2013; FIORECORREIA; LAMPREIA, 2012; GÓMEZ; TORRES; ARES, 2009; TONELLI, 2011).
Sobre a epidemiologia, Choto (2007) afirma que a análise da prevalência do autismo é uma questão confusa devido à falta de exatidão dos diagnósticos, à imprecisão nas definições e à variedade de instrumentos utilizados para o diagnóstico. Os dados sobre a prevalência não são exatos e, nas duas últimas décadas, o número passou de quatro a cada 10.000 para 62 a cada 10.000 (BARONCOHEN, 2008; ELSABBAGH et al., 2012). Para estudiosos da área (PEREIRA; RIESGO; WAGNER, 2008; SILVA, M.; MULICK, 2009), esse aumento seria explicado por fatores como a concepção de espectro, que engloba não apenas casos extremos, mas também casos mais leves, e o fato de os profissionais estarem mais bem preparados em termos de treinamento e formação, contribuindo para o diagnóstico.

Considerando a importância de estimular precocemente habilidades e de favorecer as interações sociais, a inclusão escolar dessas crianças tem sido indicada por profissionais de diferentes áreas. Entretanto, os dados encontrados na literatura sobre essa temática não são conclusivos, pois, segundo Bosa (2006), não há uma resposta final para a questão da escolarização de crianças autistas, uma vez que não há estudos comparativos metodologicamente bem controlados nesta área.

Embora a inclusão escolar seja questionada por alguns profissionais, devido às características da síndrome, o presente trabalho considera a importância da inclusão escolar para as crianças com espectro autista apoiado em estudos que reconhecem essa prática como sendo realizável e possível (BAPTISTA; BOSA, 2002; CAMARGO; BOSA, 2012; FIAES; BICHARA, 2009; LAGO, 2007; LIRA, 2004; ORRÚ, 2007; SANINI; SIFUENTES; BOSA, 2013; SERENO, 2006). Esses estudos apontam para os benefícios das vivências escolares tanto em termos de interações sociais quanto do desenvolvimento de habilidades cognitivas nas crianças desse espectro, apesar de também admitirem as dificuldades relacionadas à prática inclusiva.

Nessa perspectiva teórica, cita-se autores como Rosin-Pinola e Del Prette (2014), Colombi et al. (2009), Vygotsky (2007), Lampreia (2007), Hobson (2004) e Garton (1992) ao destacarem a importância do ambiente interpessoal para aquisição de habilidades no desenvolvimento. De acordo com Momberger (2007), Vygotsky pode ser considerado como um dos pioneiros na proposição de práticas inclusivas. Em sua obra sobre "defectologia", o referido autor realizou estudos comparativos acerca do desenvolvimento envolvendo crianças com e sem necessidades especiais, tendo como premissa a tese de que as leis que regem o desenvolvimento dessas crianças eram essencialmente as mesmas. O estudioso defendia a escola inclusiva e a não segregação social dessas crianças, embora reconhecesse o valor e a importância da educação especial.

Atualmente, entende-se inclusão escolar como uma prática que envolve atenção personalizada e respeito às características individuais de cada educando, oferecendolhe oportunidades para o seu desenvolvimento integral. De acordo com Sekkel, Zanelatto e Brandão (2010), 
movimentar a instituição para uma prática inclusiva parece ser um trabalho de articulação no sentido de criar escuta, possibilidades de compartilhamento e intervenção orientadas pelo compromisso com os valores humanos.

A esse respeito, Tessaro et al. (2005) compreendem a viabilidade da prática inclusiva desde que se entenda a complexidade de tal processo, que requer muito investimento e comprometimento, principalmente dos órgãos governamentais. Os posicionamentos da Lei de Diretrizes e Bases da Educação Nacional (BRASIL, 1996), do Estatuto da Criança e do Adolescente (BRASIL, 1990) e da Política Nacional de Educação Especial (BRASIL, 2007) corroboram o que foi proposto pela Conferência Mundial de Educação para Todos (1990) e pela Declaração de Salamanca (1994), que defendem a importância de se universalizar o acesso à educação e promover a equidade nesse sentido (LOURENÇO, 2010; RIBEIRO, 2003).

Aponta-se, assim, para a relevância de os profissionais das escolas se apropriarem da proposta de inclusão escolar, sobretudo o professor, pois se concorda com Batista e Enumo (2004) quando afirmam que este é o profissional que lida diretamente com o aluno, sendo o agente mais eficaz no processo de inclusão. Nesse sentido, o estudo de Ferreira (2007) apontou que o sucesso ou o insucesso da aprendizagem da criança com necessidades educativas especiais é, muitas vezes, reflexo da intervenção pedagógica e do perfil do professor.

A necessidade de formação de professores é mencionada por diversos autores como um aspecto imprescindível no processo de inclusão (BORGES, 2000; FERREIRA, 2003; RIBEIRO, 2003; ROSIN-PINOLA; DEL PRETTE, 2014; SILVA, M., 2003). Para Sant'Ana (2005), há ainda a necessidade de supervisão e orientação, de maneira que o professor seja ajudado a refletir sobre sua prática, para que compreenda suas crenças em relação ao processo, tornando-se um pesquisador de suas ações.

A esse respeito, cita-se Rosin-Pinola e Del Prette (2014) ao abordarem a complexidade que envolve a temática "inclusão escolar", sobretudo ao considerar a variabilidade de problemas que envolvem a educação brasileira. As referidas autoras analisaram criticamente alguns materiais publicados pelo Ministério da Educação (MEC) e destacaram que estes materiais são apresentados de forma vaga e pouco contextualizada. Conforme as autoras, esses materiais precisariam ser acompanhados de orientações sobre ações e habilidades que o professor deve apresentar para criar condições de aprendizagem para os alunos.

A falta de clareza em relação aos materiais publicados pelo MEC se estende a várias questões relacionadas à inclusão, pois há uma distância entre os aspectos legais e os aspectos práticos. Algumas dúvidas perpassam entre aqueles que lidam diretamente com a inclusão escolar, a saber: Quantas crianças com necessidades especiais podem ser matriculadas em uma mesma sala de aula? Elas têm direito à acompanhantes na escola? Quem deve custear? O Atendimento Educacional Especializado tem sido realizado por profissionais devidamente selecionados e capacitados? As crianças têm acesso ao material didático devidamente adaptado? Nessa direção, Rosin-Pinola e Del Prette (2014) defendem o papel das assessorias de profissionais especializados com vistas a instrumentalizar os professores.

De acordo com Macedo et al. (2014), a concretização dos princípios da inclusão escolar no Brasil é dificultada por fatores políticos, sociais, econômicos e, sobretudo, históricos e culturais. Segundo os autores, as instituições refletem em seu funcionamento a estrutura de uma sociedade complexa, contraditória e individualizante. Nesse sentido, as práticas excludentes ainda prevalecem nas escolas a partir de pessoas que não concebem as possibilidades das práticas inclusivas, que não contribuem com a consolidação de uma sociedade mais justa e solidária e que não buscam superar as contradições que a constituem.

Em face das especificidades inerentes ao Transtorno do Espectro Autista, as práticas inclusivas nesta área envolvem uma série de variáveis, a saber: disponibilidade da direção em receber e realizar as adequações necessárias; experiência, formação, crenças e características pessoais dos professores; características dos demais alunos inseridos na sala de aula; participação das famílias; e, principalmente, características da criança do espectro autista em termos de diferentes níveis de comprometimento nas áreas de comportamento, linguagem e socialização.

Ademais, são consideradas as diferenças nas práticas escolares que ocorrem a partir de variações históricas, culturais e contextuais, como também as discrepâncias que permeiam a teoria e a prática, o discurso e a realidade de cada instituição escolar. Tais aspectos devem ser considerados, sobretudo com a aprovação da Lei $n^{\circ}$. 12.764/2012, que institui a Política Nacional de Proteção dos Direitos da Pessoa com Transtorno do Espectro Autista (BRASIL, 2012), garantindo a esse indivíduo, dentre outros direitos, o acesso à educação.

De acordo com Lago (2007), embora os professores relatem dificuldades em superar os desafios que se apresentam no cotidiano e queixas em relação à formação para trabalhar com crianças com esta condição, há, atualmente, por parte desses professores, relatos de experiências bem-sucedidas com crianças que frequentam escolas regulares. Estes profissionais destacam que as crianças autistas têm apresentado bons resultados em relação à apropriação de conhecimentos veiculados na escola.

Cabe refletir ainda sobre o papel dos psicólogos escolares em contribuírem para a consolidação do processo de inclusão escolar dos alunos com necessidades educativas especiais. Conforme apontam alguns autores (DAZZANI, 2010; SILVA; MENDES, 2012), a Psicologia Escolar ou Educacional tradicionalmente tem baseado a sua atuação em um modelo médico de prestação de serviço, envolvendo avaliação, diagnóstico, encaminhamento e tratamento dos alunos. No entanto, tais autores consideram que essas ações limitam a atuação 
do psicólogo no contexto escolar, uma vez que muito tempo é despendido na busca de diagnóstico, enquanto essas informações têm pouca importância na seleção e no planejamento de intervenções educacionais efetivas.

Apesar dessas críticas ao modelo tradicional da Psicologia Educacional baseado na concepção da clínica psicológica, é importante mencionar que a literatura destaca que o conhecimento produzido pela Psicologia pode contribuir com as práticas educativas, inclusive para a melhoria da escola para todos (DAZZANI, 2010; MATTOS; NUERNBERG, 2011; SILVA, A.; MENDES, 2012). Ao conceber a escola como um espaço interdisciplinar, considera-se que o psicólogo que atua no contexto escolar deve estar preparado para trabalhar de forma colaborativa com os professores, com a família, com a comunidade e com os demais profissionais que fazem parte da ação educativa no planejamento de intervenções que sejam capazes de melhorar a qualidade de vida dos alunos, promovendo o seu desenvolvimento e aprendizagem.

Gomes e Souza (2011), ao discutirem os desafios da Psicologia no que diz repeito à educação inclusiva, apontam para a necessidade de os psicólogos escolares pautarem a sua atuação em práticas contextualizadas, reflexivas e críticas, que sejam comprometidas socialmente com os alunos com necessidades educativas especiais, assim como com os seus professores, partindo, sobretudo, do respeito às diferenças e em defesa dos direitos desses alunos ao atendimento de suas necessidades e promoção do seu desenvolvimento.

Destaca-se também a relevância das concepções dos pais e dos professores sobre essas crianças, considerando suas implicações nas práticas e interações estabelecidas com elas, assim como no próprio desenvolvimento infantil (RIBAS JR.; SEIDL-DE-MOURA; BORNSTEIN, 2007; SEIDL-DE-MOURA et al., 2004). Segundo Seidl-deMoura et al. (2004), as concepções sobre as capacidades da criança atuam como mediadores, influenciando a interação que será estabelecida com ela, na forma de práticas de cuidado, tendo efeitos sobre o comportamento da criança e sobre o seu desenvolvimento.

Nesse sentido, o presente estudo teve como objetivo principal analisar as concepções de pais e de professores acerca da criança autista e do processo de inclusão escolar, considerando as influências que as concepções acerca do autismo e da inclusão escolar exercem sobre as práticas escolares, assim como sobre a participação da família nesse processo.

\section{Método}

\section{Participantes}

Participaram deste estudo seis professoras de quatro escolas regulares particulares da cidade de João Pessoa-PB, as quais tinham em suas salas crianças com diagnóstico de Transtorno do Espectro Autista, com idades variando entre três e sete anos. Além das professoras, participaram do estudo oito genitores, sendo seis mães e dois pais. As crianças com diagnóstico de espectro autista apresentavam quadros de leves a moderados, sendo que três delas eram não verbais e todas realizavam intervenções terapêuticas diárias com profissionais como: fonoaudióloga, psicopedagoga, educador físico e fisioterapeuta.

\section{Instrumentos}

Com o objetivo de favorecer maior apreensão das informações relatadas pelos indivíduos entrevistados, foram utilizadas entrevistas semiestruturadas com pais e professoras registradas através de um minigravador.

\section{Procedimentos}

Inicialmente, entrou-se em contato com os pais das crianças do espectro autista a fim de obter a permissão para a participação no estudo. Posteriormente, foram contatados os diretores das escolas visando ao esclarecimento da pesquisa, assim como para obter a autorização para a realização do estudo com as professoras da instituição. Em seguida, as professoras foram contatadas com os mesmos procedimentos: a apresentação da pesquisadora e dos objetivos do estudo, dos procedimentos para coleta e análise dos dados, além do esclarecimento dos compromissos éticos adotados e dos termos de consentimento para participação. O presente estudo passou pela apreciação do Comitê de Ética em Pesquisa do Centro de Ciências da Saúde (CCS) da Universidade Federal da Paraíba (UFPB), do qual recebeu aprovação sob o protocolo de número 480/10.

Após consentimentos das famílias, das escolas e das professoras, foi iniciada a etapa das entrevistas, que foram realizadas individualmente em um ambiente reservado, com média de 30 minutos de duração. As entrevistas gravadas foram transcritas e submetidas à técnica de Análise de Conteúdo Categorial-Temática, proposta por Bardin (1977).

Com a análise, foram estabelecidas duas categorias: “concepções dos professores" e "concepções dos pais". A análise também permitiu a composição de subcategorias. Sendo assim, quanto às concepções dos professores, foram identificadas as seguintes subcategorias: concepção de criança com espectro autista; experiência de trabalhar com uma criança do espectro autista; concepção de inclusão escolar; estratégias utilizadas para favorecer a inclusão dessas crianças; e participação da família. No que diz respeito às concepções dos pais, as subcategorias foram as seguintes: concepções parentais sobre espectro autista do filho; expectativas em relação ao processo de inclusão escolar; descrição do processo de inclusão do filho; participação da família; profissionais que consideram importantes; e percepção de mudanças no comportamento do filho. Os resultados do presente trabalho foram analisados e discutidos com base na literatura da área e nas práticas e concepções dos profissionais e familiares. 


\section{Resultados}

\section{Concepções dos professores}

A análise das verbalizações das professoras revelou que, em relação à "concepção de criança com espectro autista", a maioria demonstrou estar reformulando suas concepções a partir das experiências estabelecidas com estas crianças no cotidiano escolar. Embora tais concepções abordem as dificuldades das crianças, partem de aspectos positivos que envolvem as possibilidades e os resultados dos esforços dispensados com o trabalho de inclusão, muito embora duas das professoras tenham mencionado aspectos que remetem a práticas mais assistencialistas.

A gente só escutava falar assim, que o autista era uma pessoa que era só ele, só vivia ele, e, quando eu cheguei aqui, eu vi que não era nada disso [...], a gente começa a entender que eles não são tão individualistas, porque ele chega, abraça, são carinhosos, entendeu? Mas claro que eles têm o momento deles.

Quanto à categoria "experiência de trabalhar com uma criança do espectro autista", a maioria das professoras, mesmo reconhecendo as dificuldades inerentes à prática inclusiva, destacaram aspectos positivos, assim como os êxitos obtidos pelas crianças. Outra questão observada foi a ênfase nas características pessoais e na maneira de lidar com essa experiência não apenas em termos profissionais, mas principalmente pessoais.

Está sendo muito dificil, precisa de muito interesse, muito compromisso [...]. Se você for pensar somente no que é autismo, não sai não, não consegue não, mas se pensar no amor, no carinho, na solidariedade, tô conseguindo muita coisa, de verdade. Tô me sentindo realizada e bem.

Sobre a "concepção de inclusão escolar", foram relatados aspectos que envolvem esta prática, tais como: necessidade de apoio de outros profissionais, formação profissional, características pessoais e integração da criança ao grupo. Entretanto, metade das professoras destacou a importância da família e da sociedade nesse processo. Uma delas demonstrou uma concepção mais restrita, enfatizando apenas a inserção da criança na escola.

Bom, para mim, inclusão é eles estarem aqui na escola, na escola dita normal e interagindo com as outras crianças, mas o importante para mim é que eles estejam no ambiente e estejam interagindo com os outros, vendo a rotina de uma escola, participando e também tendo apoio da família e do pessoal do colégio, a orientação do colégio é muito importante.

No tocante às "estratégias utilizadas para favorecer a inclusão dessas crianças", todas as professoras mencionaram práticas que envolvem a socialização e a integração das crianças com espectro autista aos demais alunos. Mesmo relatando práticas voltadas para a aprendizagem acadêmica, as professoras em seus discursos associaram nesses momentos intervenções que favorecem a socialização. Também foram relatadas a utilização de músicas, imagens, jogos e materiais concretos como estratégias que favorecem o processo de ensino-aprendizagem dessas crianças. Uma das professoras salientou a importância da sensibilidade, uma vez que esta característica influencia positivamente a elaboração de estratégias.

Muito concreto, eles só tem progresso se você começar do concreto. Muito concreto, muito carinho, muita paciência, muito compromisso, muito amor, você vê resultado. [...] Insistência, todos os dias, todos os dias [...], se você fugir, não consegue, com essas crianças tem que ter rotina: todo dia roda de conversa, todo dia hora do lanche, todo dia hora de ir, hora de voltar, todos os passos detalhadamente. [...] Se eu tivesse tudinho e não tivesse sensibilidade, não tinha nada. Eu percebo como eles aprendem, o professor tem que saber de cada aluno como eles aprendem [...]. E outra coisa, tem que ter domínio de sala [...], o autista tem audição muito aguçada, então qualquer barulho perturba logo.

A respeito das verbalizações das professoras sobre a "participação da família”, a maioria destacou a presença das famílias no processo de inclusão escolar do filho com espectro autista, como exemplifica o relato de uma professora: "Bom, a família dele é bem participativa, eles realizam sempre as tarefas de casa, sempre dão atenção a tudo que é pedido na agenda, sempre dão retorno".

\section{Concepções dos pais}

Em relação às entrevistas realizadas com os pais, verificou-se que as "concepções parentais sobre espectro autista" revelaram que estas são influenciadas pelas características dos seus filhos. Assim, os pais adotaram conceitos menos rígidos, compreendendo os esforços de que o filho dispõe para interagir ou mesmo interpretando os comportamentos e as dificuldades, ao invés de rotulálos: "É uma criança que busca soluções nela mesma e acha que ela mesma se basta [...]. Deve ser muito dificil, é como um estrangeiro, né? A pessoa chega num país e ninguém sabe falar com ele".

É uma criança que tem, assim, realmente muita dificuldade, principalmente, eu acho, de socializar; se a gente for falar de imaginação é muito relativo, porque, às vezes, a criança tem imaginação, mas até pela falta de socialização ela não consegue demonstrar aquela imaginação que tem, entendeu? [...]. Uma criança assim, mais arredia, que gosta de, não é nem de ficar sozinha, é de ficar com suas coisas [...], não compartilha muito comigo as coisas que ele está vendo, que ele está fazendo, ele quer que eu esteja junto vendo, não gosta de estar sozinho.

Quando disseram 'autismo', eu pensei aquela coisa clássica, que ele não ia fazer nada, que ele não ia estudar, que ele não ia crescer, que ele não ia entender nada, que iria ficar só sentado se balançando sem entender nada. Mas quando eu vi não é assim, aí eu vejo que o autismo é uma síndrome, que tem aquela tríade da comunicação, socialização [...] e que não é tão difícil [...]. Então eu entendo o conceito de autismo, mas não acredito que seja tão duro como eles escrevem.

No que diz respeito às "expectativas em relação ao processo de inclusão escolar do filho", embora todos eles tenham exposto metas quanto à socialização e aquisição de comportamentos por meio de imitação 
das demais crianças, mais da metade dos entrevistados demonstrou expectativas voltadas para aprendizagens acadêmicas, como alfabetização, por exemplo. Um deles abordou a importância da aprendizagem de comportamentos de independência, e uma mãe destacou o simples fato de a criança vivenciar experiências de indivíduos da mesma faixa etária.

Foi mais assim, para socializar, né? Não era nem tanto assim, para aprender nada. Como ele é uma criança muito hiperativa, eu achava muito difícil alguém conseguir ensinar alguma coisa para ele; eu sozinha em casa já é dificil [...]. Eu queria que ele experimentasse as coisas que uma criança normal experimenta, tanto que eu não fiz muita questão de adaptar as atividades.

Até mesmo se igualar com as outras crianças, mas este é que é o problema, enquanto ele não falar, a gente não vai ter certeza, de repente a gente pode até estar falando estas coisas aqui e ele estar entendendo praticamente tudo.

Meu sonho é que ele se forme um dia, chegue ao terceiro grau e ele se forme. Ele tem mostrado que esse meu sonho talvez seja possivel, porque ele tem acompanhado muito bem na sala de aula a parte de aprendizado...

Quanto à "descrição do processo de inclusão do filho", todas as mães demonstraram satisfação, sendo que uma delas destacou o investimento em uma profissional especializada atuando como auxiliar em sala de aula; outra ressaltou os comportamentos de receptividade dos outros pais com seu filho; e outras duas destacaram características específicas da professora. Ainda houve uma mãe que salientou a sua própria participação como sendo de fundamental importância para estimular o envolvimento da professora com a inclusão do seu filho. "Excelente, principalmente devido à participação intensa da professora, que quer vê-lo incluído e aprendendo dentro da sala de aula".

Com relação à opinião sobre a "participação da família", todas admitiram a importância do seu papel para que a inclusão escolar dos seus filhos se efetive. Interessa ressaltar que uma das mães colocou a sua importância não só em termos do seu filho, mas também no sentido de ajudar mães de crianças que estão na fase inicial, muitas vezes sem o diagnóstico. Outra mãe afirmou que, embora estimule seu filho, prefere não interferir nas questões pedagógicas. Duas mães destacaram seus papéis na promoção de treinamentos para equipe escolar.

O papel da familia é grande, é bem grande [...]. Achar que incluir é somente colocar na escola é estar se omitindo, né?

[...]. Eu acho interessante realmente a gente abrir a mente dessas pessoas, explicar como e treinar mesmo para poder lidar com nossos filhos.

Quanto aos "profissionais que consideram importantes" para a realização da inclusão, foram mencionados: fonoaudióloga (6); psicopedagoga (3), psicóloga (3), pedagoga especializada (1), professoras (1), facilitadoras (1), diretor (1), educador físico (1) e fisioterapeuta (1). Por fim, em relação à "percepção de mudanças no comportamento do filho", todas destacaram mudanças positivas em seus filhos, sobretudo em relação à aprendizagem acadêmica e de modelos de comportamento, além da satisfação da criança em participar e ir à escola.

Ele vai para a escola feliz, não joga mais a roupa fora. [...] Ele melhorou bastante, a socialização [...]. Ele tenta participar [...]. Não prestar atenção nas coisas, hoje ele melhorou muito [...]. A gente chamava e ele ignorava totalmente, e hoje ele atende [...]. Não era carinhoso [...]. Hoje, quando a gente sai, ele vem dar beijo.

\section{Discussão}

Os resultados deste estudo destacam a importância da inclusão escolar das crianças com espectro autista, mostrando, por meio de relatos dos pais e dos professores, possibilidades em relação a essa prática, que, muitas vezes, é questionada em função das dificuldades próprias do autismo.

Os discursos das professoras demonstram a ruptura entre os conceitos iniciais que tinham sobre o autismo - em sua maioria, percebiam as crianças como isoladas, arredias e avessas a atitudes de carinho - e os conceitos que têm após a experiência com essas crianças no cotidiano escolar. Considera-se que esse dado corrobora a afirmação de Camargo e Torezan (2004), de que as concepções sobre determinado fenômeno podem ser transformadas a partir da interação direta com o outro.

Essa questão remete a duas discussões de suma importância: a primeira delas é o estigma do autismo, capaz de rotular as crianças, interferindo nas ações a elas dirigidas. Já a segunda se refere à importância de essas crianças serem inseridas nas escolas regulares, tendo oportunidades educativas assim como as demais, demonstrando suas habilidades e ajudando profissionais a redimensionarem suas concepções e práticas.

Não se pretende, com o presente trabalho, adotar uma visão romântica acerca da inclusão escolar de crianças autistas, negando ou não revelando as dificuldades que permeiam esse processo, sobretudo conhecendo a existência de diferentes graus de autismo. Do contrário, assim como foi posto pelas professoras, pretende-se reconhecer essas dificuldades e também ressaltar as possibilidades e os avanços conquistados por essas crianças a partir da rotina escolar, de comportamentos de imitação, da perseverança e do comprometimento das professoras, bem como das estratégias por elas utilizadas e também do envolvimento da família.

Conforme abordado neste trabalho, além das dificuldades relacionadas à inclusão de crianças autistas, há toda a complexidade de um cenário educacional, histórico, cultural e social que precisa ser considerada. Nessa perspectiva, autores como Rosin-Pinola e Del Prette (2014) mencionam as dificuldades em relação à efetivação de práticas inclusivas no Brasil pelo cenário atual da educação e das instituições. Porém, as autoras entendem que esse conjunto de problemas não justifica as dificuldades em relação à inclusão. A gama de problemas na educação brasileira faz parte de um conjunto de contradições que precisam ser modificadas nas escolas, dentre as quais a inclusão é apenas uma delas. 
Em face disso, discute-se a inserção dos psicólogos nos contextos escolares, bem como seu compromisso social e ético frente às demandas da atualidade. A esse respeito, autores como Amendola (2014) advogam que o psicólogo deve adotar uma postura crítica, reflexiva e criativa, no sentido de questionar suas ações e se posicionar frente as demandas da atualidade, não reproduzindo ações opressivas ou na linha da normalização. Essa postura deve ser contemplada desde a formação desses profissionais, instrumentalizando para aceitação dos desafios, construção e reconstrução de teorias e, sobretudo, discussão de hipóteses contextualizadas com a realidade contextual e as demandas sociais.

Em relação às estratégias relatadas pelas professoras, residem outros aspectos importantes, a saber: a adoção de estratégias baseadas na intuição, algumas vezes com pouco respaldo teórico e pouca orientação de profissionais capacitados; e, nos casos de treinamentos ou supervisões, estas foram custeadas pelos pais. Reconhece-se, assim, a importância de os profissionais da Psicologia estarem preparados para dar apoio psicopedagógico aos docentes e de serem eles, juntamente com os pedagogos e os docentes, os profissionais que podem construir novos cenários educativos para crianças com necessidades educativas especiais dentro das escolas. De acordo com Andrada (2005), uma das atribuições do psicólogo escolar consiste em trabalhar junto à equipe pedagógica criando espaços semanais de diálogos com os professores, para que juntos cheguem a novas versões de um mesmo fenômeno, eliminando a possibilidade de estigmatizar os alunos com dificuldades.

No que se refere aos discursos dos pais, inicialmente, o estudo se propunha a realizar entrevistas com as mães, uma vez que estas geralmente têm mais informações e são as maiores responsáveis pela vida escolar dos seus filhos. Entretanto, em duas famílias, as mães solicitaram a presença do marido, em virtude de sua participação e conhecimento a respeito da criança. Nesse sentido, a pesquisa de Sifuentes e Bosa (2010), que trata sobre coparentalidade de pais de crianças pré-escolares com autismo, revelou que as tarefas parentais não são compartilhadas de forma igualitária entre o casal e que isso ocorre em função das demandas próprias do autismo e da forma como a família se organiza para atender a essas demandas.

Os relatos dos pais do presente estudo revelam as discrepâncias entre a percepção que têm dos seus filhos e as crianças autistas descritas nos manuais diagnósticos. Destacam-se os relatos de presença de contato visual, manifestações de comportamentos deliberados de carinho ou reações diante dos pais, por parte das crianças autistas, que se opõem à indiferença geralmente associada ao autismo. Essas discrepâncias ocorrem em função da generalização dos sintomas e da consideração pouco abrangente dos comportamentos em termos de como, por que e com que frequência ocorrem e, principalmente, em que contextos e com quem ocorrem.

A esse respeito, concorda-se com Baptista e Bosa (2002) quando afirmam que é preciso ampliar a concepção acerca dos indivíduos com autismo, visto que, por muito tempo, prevaleceu a noção de que essas pessoas são alheias ao mundo ao seu redor, não tolerando contato físico, não fixando o olhar nas pessoas e interessando-se mais por objetos do que por pessoas. Conforme os autores, atualmente há evidências de que nem todos os autistas mostram aversão ao toque ou isolamento e que os olhares são mais frequentes do que se imagina; o que ocorre é que são breves e, por isso, muitas vezes imperceptíveis.

De maneira geral, os pais demonstraram satisfação em relação à inclusão escolar de seus filhos, sobretudo por perceberem felicidade nas crianças ao irem à escola. Apesar disso, muitos apontaram para a necessidade de maior preparo dos profissionais que lidam com seus filhos e a importância de outros profissionais inseridos na escola para darem suas contribuições práticas e auxiliarem no desenvolvimento integral dos seus filhos.

Vale ressaltar que o fato de os pais terem demonstrado expectativas voltadas para aprendizagens acadêmicas dois deles acreditando até mesmo que eles chegariam a se igualar às demais crianças - sugere que essas expectativas se devem ao nível leve-moderado de comprometimento dos seus filhos, da pouca idade das crianças, das respostas que elas vêm demonstrando e dos esforços da escola e da família. De acordo com Bosa (2006), as famílias modificam suas expectativas e valores com relação ao tratamento de seu filho segundo a fase de desenvolvimento da criança e do contexto familiar.

Ainda sobre as expectativas de socialização e aprendizagem acadêmica por parte dos pais, cita-se RosinPinola e Del Prette (2014) ao destacarem a relevância que as habilidades sociais educativas podem ter sobre o processo de inclusão, uma vez que os avanços no repertório social e acadêmico dos alunos favorecem suas interações no contexto escolar. Entretanto, as referidas autoras ressaltam a necessidade de instrumentalizar e assessorar os professores para criarem condições de promoverem o desenvolvimento dos seus alunos com necessidades educativas especiais.

Sobre a participação dos pais no processo de escolarização dos seus filhos, todos admitiram a importância do seu papel para que a inclusão escolar se efetive, o que corrobora os relatos das professoras, que ressaltaram a participação desses pais em diferentes demandas do cotidiano escolar. Nessa direção, o estudo de Panerai et al. (2009) sobre a inclusão de crianças autistas em escolas regulares aborda a importância dos pais na participação da educação dessas crianças, afirmando que, quando os pais tomam para si a responsabilidade da educação de seus filhos, são capazes de promover muitos aspectos positivos na promoção da aprendizagem e do desenvolvimento das crianças.

Tendo em vista os aspectos mencionados, destacase o papel do psicólogo enquanto agente de mudanças no processo de inclusão escolar, mesmo porque as transformações dos processos educativos e as necessárias mudanças que a educação demanda constituem compromisso essencial dos psicólogos com a educação (MARTINEZ, 2009; MATTOS; NUERNBERG, 2011). 
Esses profissionais podem atuar não apenas junto à criança autista, mas também junto à família, aos professores e à equipe escolar, às demais crianças e aos seus pais. Como exemplo disso, cita-se instrumentalizar e promover espaços de formação continuada junto aos professores para que estes possam identificar com maior critério crianças com características desse transtorno, em face do aumento na prevalência de casos e, principalmente, da importância do diagnóstico e da intervenção precoces. Cabe ao psicólogo capacitar os professores, realizar supervisões, desenvolver trabalhos junto às famílias e às crianças, favorecendo o processo de inclusão.

Das quatro escolas pesquisadas, duas contavam com esse profissional em seu quadro de pessoal. Em uma das escolas, a psicóloga foi citada pela professora por não ter realizado orientações e ter se omitido, apoiando-se na justificativa de não ter tido experiência nessa área e por ter tido pouco contato com essas questões na faculdade. Aponta-se, assim, para a importância da Psicologia Escolar e do seu papel no planejamento de intervenções que melhorem a qualidade de vida dos alunos, promovendo o seu aprendizado e desenvolvimento no espaço escolar (ANACHE, 2010; DAZZANI, 2010; SILVA, A.; MENDES, 2012), pois, como afirmam Mattos e Nuernberg (2011, p. 130), "uma possibilidade de parceria com a Psicologia está justamente no diálogo entre a educação e a compreensão do desenvolvimento do psiquismo, possibilitando espaços reflexivos e viabilizando o entrelaçamento entre as áreas, contribuindo para propostas educacionais".

Para tanto, embora não seja objetivo deste estudo, entende-se a relevância de refletir sobre os aspectos relacionados à formação em Psicologia. Um estudo transversal realizado por Barbosa e Conti, em 2012, sobre a preparação de estudantes de Psicologia para atuarem em escolas inclusivas, aponta que há evidências de que a graduação em Psicologia não tem sido capaz de alterar o posicionamento dos estudantes quanto à educação inclusiva e de prepará-los para serem psicólogos escolares em escolas inclusivas. Ademais, poucos são aqueles que escolhem a área e poucas são as possibilidades de estágios especificamente relacionados à inclusão escolar. Contudo, as experiências pessoais e acadêmicas dos estudantes de Psicologia no contexto de inclusão escolar são de grande influência para a adoção de atitudes mais favoráveis em relação às pessoas com deficiências.

A importância de abordar as contribuições da Psicologia Escolar se dá pela possibilidade de atuação em favor da diminuição do preconceito e da discriminação, possibilitando o oferecimento de educação de qualidade a todos, sem distinção (MACEDO et al., 2014). Segundo Amendola (2014), a Psicologia precisa reconhecer a necessidade de revisar seu lugar na qualidade de ciência comprometida com o social, sendo assim, a formação deve comprometer-se com a articulação teórico-prática capaz de oferecer ao aluno uma solidez epistemológica que o prepare para a reflexão e atuação frente aos desafios e dilemas com os quais se depararão no cotidiano de suas práticas.

\section{Considerações finais}

Pretende-se, com este estudo, subsidiar orientações a pais e a profissionais, principalmente no que se refere à inclusão escolar de crianças autistas, tendo em vista que as concepções podem influenciar os comportamentos dos adultos, como também os comportamentos dessas crianças podem ser influenciados considerando-se os contextos interativos, a mediação do adulto e, sobretudo, as particularidades de cada criança.

É preciso destacar a importância do tema autismo e a possibilidade de educação e inclusão, tendo em vista o aumento do número de casos, a demanda educacional que cada vez mais preconiza a inclusão dessas crianças em escolas regulares e os benefícios que podem ser alcançados através dessa prática. Pensando em promover avanços na discussão dessa temática e acreditando nos efeitos positivos dessa ação em várias dimensões, foi desenvolvido o presente trabalho.

Conhecer e investigar as concepções de pais e professores de crianças autistas foi imprescindível para entender que a garantia do sucesso da inclusão escolar se dá por meio da participação efetiva das duas partes. Essa experiência permitiu o esclarecimento de que a inclusão necessita não somente de conhecimento teórico acerca do autismo e das estratégias de trabalho, mas também de uma predisposição da família e da escola em aceitar e trabalhar de maneira positiva com tais crianças. Estar aberto à experiência é fundamental, pois, muitas vezes, a falta de formação e de contato com a síndrome leva à resistência à mudança e à adoção de atitudes negativas em relação à inclusão. Dessa forma, destacase o papel do psicólogo escolar, no sentido contribuir para a formação continuada dos professores, na forma de assessoria e de acompanhamento psicopedagógico, bem como para oferecer treinamento aos demais funcionários da instituição, além de realizar trabalhos que promovam apoio psicológico aos pais da criança.

Considerando o impacto positivo das intervenções do psicólogo no processo de inclusão escolar, sugere-se a realização de pesquisas envolvendo esses profissionais, analisando as práticas que eles têm desenvolvido na área de inclusão escolar e as suas concepções.

\section{Referências}

AMENDOLA, M. F. Formação em psicologia, demandas sociais contemporâneas e ética: uma perspectiva. Psicologia: Ciência e Profissão, Brasília, v. 34, n.4, 971-983, out.-dez. 2014. Cross ${ }^{\text {Ref. }}$

AMERICAN PSYCHIATRIC ASSOCIATION. Diagnostic and Statistical Manual of Mental Disorders. $5^{\text {th }}$ Ed. Arlington: American Psychiatric Publishing, 2013.

ANACHE, A. A. Psicologia escolar e educação especial: versões, inserções e mediações. Em Aberto, Brasília, v. 23, n. 83, p. 73-93, mar. 2010. Disponível em: <http://emaberto.inep. gov.br/index.php/emaberto/article/view/2252/2219>. Acesso em: 28 ago. 2013. 
ANDRADA, E. G. C. Novos paradigmas na prática do psicólogo escolar. Psicologia: Reflexão e Crítica, Porto Alegre, v. 18, n. 2, p. 196-199, maio/ago. 2005. Cross ${ }^{\text {Ref. }}$

ASSUMPÇÃO JR., F. B. et al. Reconhecimento facial e autismo. Arquivos de Neuro-Psiquiatria, São Paulo, v. 57, n. 4, p. 944-949, dez. 1999. Cross ${ }^{\text {Ref. }}$

ASSUMPÇÃO JR., F. B.; PIMENTEL, A. C. M. Autismo infantil. Revista Brasileira de Psiquiatria, São Paulo, v. 22, supl. 2, p. 37-39, 2000. Cross ${ }^{\text {Ref. }}$

BAPTISTA, C. R.; BOSA, C. A. Autismo e Educação: reflexões e propostas de intervenção. Porto Alegre: Artes Médicas, 2002.

BARBOSA, A. J.; CONTI, C. F. Formação em psicologia e educação inclusiva: um estudo transversal. Psicol. Esc. Educ. Maringá, v. 15, n. 2, p. 231-234, dez. 2011. Cross ${ }^{\text {Ref. }}$

BARDIN, L. Análise de conteúdo. Lisboa: Edições 70, 1977.

BARON-COHEN, S. Autism and Asperger syndrom. Oxford: Oxford University Press, 2008.

BATISTA, M.; ENUMO, S. Inclusão escolar e deficiência mental: análise da interação social entre companheiros. Estudos de Psicologia, Natal, v. 9, n. 1, p. 101-111, jan.-abr. 2004 Cross ${ }^{\text {Ref. }}$

BORGES, M. Autismo - um silêncio ruidoso: perspectiva empírica sobre o autismo no sistema regular de ensino. 2000. $117 \mathrm{f}$. Monografia (Curso de estudos superiores especializados em educação especial)-Escola Superior de Educação Jean Piaget de Almada, Almada, 2000.

BOSA, C. A. Autismo: intervenções psicoeducacionais. Revista Brasileira de Psiquiatria, São Paulo, v. 28, supl. 1, p. 47-53, maio 2006. Cross ${ }^{\text {Ref }}$

BOSA, C.; CALLIAS, M. Autismo: breve revisão de diferentes abordagens. Psicologia: Reflexão e Crítica, Porto Alegre, v. 13, n. 1, p. 167-177, 2000. Cross ${ }^{\text {Ref. }}$

BOYD, B. A. et al. Relationships among repetitive behaviors, sensory features, and executive functions in high functioning autism. Research in Autism Spectrum Disorders, v. 3, n. 4, p. 959-966, Oct-Dec. 2009. Cross ${ }^{\text {Ref. }}$

BRASIL. Presidência da República. Casa Civil. Subchefia para Assuntos Jurídicos. Lei $n^{\circ} 8.069$, de 13 de julho de 1990. Dispõe sobre o Estatuto da Criança e do Adolescente e dá outras providências. 1990. Disponível em: <http://www. planalto.gov.br/ccivil_03/leis/L8069.htm>. Acesso em: 22 ago. 2013.

BRASIL. Presidência da República. Casa Civil. Subchefia para Assuntos Jurídicos. Lei $n^{\circ}$ 9.394, de 20 de dezembro de 1996. Estabelece as diretrizes e bases da educação nacional. 1996. Disponível em: <http://www.planalto.gov.br/ccivil_03/ leis/L9394.htm>. Acesso em: 22 ago. 2013.

BRASIL. Ministério da Educação. Secretaria de Educação Especial. Política Nacional de Educação Especial na Perspectiva da Educação Inclusiva: documento elaborado pelo Grupo de Trabalho nomeado pela Portaria Ministerial $n^{\circ}$ 555, de 5 de junho de 2007, prorrogada pela Portaria ${ }^{\circ} 948$, de 09 de outubro de 2007. 2007. Disponível em: <http://peei.mec.gov. br/arquivos/politica_nacional_educacao_especial.pdf $>$. Acesso em: 22 ago. 2013.
BRASIL. Presidência da República. Casa Civil. Subchefia para Assuntos Jurídicos. Lei no 12.764, de 27 de dezembro de 2012. Institui a Política Nacional de Proteção dos Direitos da Pessoa com Transtorno do Espectro Autista; e altera o $§ 3^{\circ}$ do art. 98 da Lei $\mathrm{n}^{\circ}$ 8.112, de 11 de dezembro de 1990. 2012. Disponível em: <http://www.planalto.gov.br/ccivil_03/_ato20112014/2012/lei/112764.htm>. Acesso em 24 ago. 2013.

CAMARGO, E. A. A.; TOREZAN, A. M. Interlocução entre pais e profissionais da área da educação especial e suas concepções sobre a deficiência mental. Revista Brasileira de Educação Especial, Marília, v. 10, n. 3, p. 337-354, set./dez. 2004.

CAMARGO, S. P. H.; BOSA, C. A. Competência social, inclusão escolar e autismo: um estudo de caso comparativo. Psicologia: Teoria e Pesquisa, Brasília, v. 28, n. 3, p. 315-324, jul./set. 2012. Cross ${ }^{\text {Ref. }}$

CARVALHEIRA, G.; VERGANI, N.; BRUNONI, D. Genética do autismo. Revista Brasileira de Psiquiatria, v. 26, n. 4, p. 270-272, dez. 2004. Cross ${ }^{\text {Ref. }}$

CHOTO, M. C. Autismo infantil: el estado de la questión. Revista Ciencias Sociales Universidad de Costa Rica, v. 116, n. 2, p. 169-180, 2007. Cross ${ }^{\text {Ref. }}$

COLOMBI, C., et al. Examining correlates of cooperation in autism: Imitation, joint attention, and understanding intentions. Autism, [S.1.], v. 13, n. 2, p. 143-163, Mar. 2009. Cross ${ }^{\text {Ref }}$

DAZZANI, M. V. M. A psicologia escolar e a educação inclusiva: uma leitura crítica. Psicologia: Ciência e Profissão, Brasília, v. 30, n. 2, p. 362-375, 2010. Cross ${ }^{\text {Ref. }}$

DUMAS, J. E. Psicopatologia da infância e da adolescência. 3. ed. Porto Alegre: Artmed, 2011.

ELSABBAGH, M., et al. Global Prevalence of Autism and Other Pervasive Developmental Disorders. Autism Research, [S.1.], v. 5, n. 3, p. 160-179, 2012. Cross ${ }^{\text {Ref. }}$

FERNANDES, F. D., et al. Fonoaudiologia e autismo: resultado de três diferentes modelos de terapia de linguagem. Pró-Fono Revista de Atualização Científica, Barueri, v. 20, n. 4, p. 26772, out./dez. 2008. Cross ${ }^{\text {Ref. }}$

FERREIRA, M. Aspectos de intervenção na área de educação física escolar e política inclusiva. In: RIBEIRO, M.; BAUMEL, R. (Org.). Educação Especial: do querer ao fazer. São Paulo: Avercamp, 2003. p. 121-132.

FERREIRA, S. O enigma da inclusão: das intenções às práticas pedagógicas. Educação e Pesquisa, São Paulo, v. 33, n. 3, p. 543-560, set./dez., 2007. Cross ${ }^{\text {Ref. }}$

FIAES, C. S.; BICHARA, D. Brincadeiras de faz-de-conta em crianças autistas: limites e possibilidades numa perspectiva evolucionista. Revista Estudos de Psicologia, Natal, v. 14, n. 3, p. 231-238, set./dez. 2009. Cross ${ }^{\text {Ref. }}$

FIORE-CORREIA, O.; LAMPREIA, C. A conexão afetiva nas intervenções desenvolvimentistas para crianças autistas. Psicologia: Ciência e Profissão, Brasília, v. 32, n. 4, p. 926941, 2012. Cross ${ }^{\text {Ref. }}$

GARTON, A. F. Social Interaction and the development of language and cognition. Hillsdale, USA: Lawrence Erlbaum, 1992. 
GOMES, C.; SOUZA, V. L. T. Educação, Psicologia Escolar e Inclusão: aproximações necessárias. Revista Psicopedagogia, São Paulo, v. 28, n. 86, p. 185-193, 2011. Disponível em: $<$ http://pepsic.bvsalud.org/scielo.php?script=sci arttext\&pid=S0103-84862011000200009>. Acesso em: 22 ago. 2013.

GÓMEZ, S. L.; TORRES, R. S. R.; ARES, E. M. T. Revisiones sobre el autismo. Revista Latinoamericana de Psicologia, Bogotá, v. 41, n. 3, p. 555-570, 2009. Disponível em: $\quad<$ http://www.scielo.org.co/scielo.php?script=sci arttext\&pid=S0120-05342009000300011\&lng=pt\&nrm $=\mathrm{iso} \&$ tlng=es $>$. Acesso em: 22 set. 2013.

GUPTA, A. R.; STATE, M. W. Autismo: genética. Revista Brasileira de Psiquiatria, São Paulo, v. 28, supl. 1, p. 29-38, maio 2006. Cross ${ }^{\text {Ref }}$

HAPPÉ, F.; RONALD, A.; PLOMIN, R. Time to give up on a single explanation for autism. Nature Neuroscience, [S.1.], v. 9, n. 10, p. 1218-1220, Oct. 2006. Cross ${ }^{\text {Ref. }}$

HOBSON, P. The Cradle of thought: Exploring the origins of thinking. Oxford: Oxford University Press, 2004.

KANNER, L. Autistic disturbance of affective contact. Nervous Child, [S.1.], v. 2, p. 217-250, 1943.

KLIN, A. Autismo e síndrome de Asperger: uma visão geral. Revista Brasileira de Psiquiatria, São Paulo, v. 28, supl.1, p. 3-11, 2006. Cross ${ }^{\text {Ref. }}$

LAGO, M. Autismo na escola: ação e reflexão do professor. 2007. Dissertação (Mestrado em Educação)-Faculdade de Educação, Universidade Federal do Rio Grande do Sul, Rio Grande do Sul, 2007.

LAMPREIA, C. Os enfoques cognitivista e desenvolvimentista no autismo: uma análise preliminar. Psicologia: Reflexão $e$ Crítica, Porto Alegre, v. 17, n. 1, p. 111-120, 2004. Cross ${ }^{\text {Ref. }}$

LAMPREIA, C. A perspectiva desenvolvimentista para a intervenção precoce no autismo. Estudos de Psicologia (Campinas), Campinas, v. 24, n. 1, p. 105-114, jan.-mar. 2007. Cross $^{\text {Ref }}$

LAMPREIA, C. Perspectivas da pesquisa prospectiva com bebês irmãos de autistas. Psicologia: Ciência e Profissão, Brasília, v. 29, n. 1, p. 160-171, 2009. Cross ${ }^{\text {Ref. }}$

LIRA, S. M. Escolarização de alunos autistas: histórias de sala de aula. 2004. Dissertação (Mestrado em Educação)-Centro de Educação e Humanidades, Universidade do Estado do Rio de Janeiro, Rio de Janeiro, 2004.

LOURENÇO, E. Conceitos e práticas para refletir sobre a educação inclusiva. Belo Horizonte: Autêntica, 2010. Série Cadernos da Diversidade.

MACHADO, M. G. et al. Alterações anátomo-funcionais do sistema nervoso central no transtorno autístico: um estudo com RNM e SPECT. Arquivos de Neuro-Psiquiatria, São Paulo, v. 61, n. 4, p. 957-961, dez. 2003. Cross ${ }^{\text {Ref. }}$

MACEDO, M. C. et al. Histórico da inclusão escolar: uma discussão entre texto e contexto. Psicologia em Estudo, Maringá, v. 19, n. 2, p. 179-189, abr./jun. 2014. Cross ${ }^{\text {Ref. }}$
MARTINEZ, A. M. Psicologia escolar e educacional: compromissos coma educação brasileira. Revista Semestral da Associação Brasileira de Psicologia Escolar e Educacional, Campinas, v. 13, n. 1, p. 169-177, jan./jun. 2009. Cross ${ }^{\text {Ref. }}$

MATTOS, L. K.; NUERNBERG, A. H. Reflexões sobre a inclusão escolar de uma criança com diagnóstico de autismo na educação infantil. Revista Educação Especial, Santa Maria, v. 24, n. 39, p. 129-142, jan./abr. 2011. Disponível em: $<$ https://periodicos.ufsm.br/educacaoespecial/article/ view/1989>. Acesso em: 11 ago. 2013.

MITCHELL, P.; O'KEEFE, K. Brief report: do individuals with autism spectrum disorder think they know their own minds? Journal of Autism and Developmental Disorders, [S.1.], v. 38, n. 8, p. 1591-1597, 2008. Cross ${ }^{\text {Ref. }}$

MOMBERGER, M. M. Inclusão no ensino superior: itinerários de vidas de acadêmicos com necessidades educacionais especiais. 2007. Dissertação (Mestrado)-Faculdade de Educação, Universidade Federal do Rio Grande do Sul, Porto Alegre, 2007.

ORRÚ, S. E. Autismo, linguagem e educação: interação social no cotidiano escolar. Rio de Janeiro: Wak, 2007.

PANERAI, S. et al. Special education versus inclusive education: the role of the TEACCH program. Journal of Autism and Developmental Disorders, [S.1.], v. 39, n, 6. p. 874-882, Jun. 2009. Cross ${ }^{\text {Ref }}$

PEREIRA, A; RIESGO, R. S.; WAGNER, M. B. Autismo infantil: tradução e validação da Childhood Autism Rating Scale para uso no Brasil. Jornal de Pediatria, Porto Alegre, v. 84, n. 6, p. 487-494, nov./dez. 2008. Cross ${ }^{\text {Ref }}$

RIBAS JR., R. C.; SEIDL-DE-MOURA, M. L.; BORNSTEIN, M. H. Cognições maternas acerca da maternidade e do desenvolvimento humano: uma contribuição ao estudo da psicologia parental. Revista Brasileira Crescimento e Desenvolvimento Humano, São Paulo, v. 17, n. 1, p. 104-113, abr. 2007. Disponível em: <http://www.revistas.usp.br/ jhgd/article/view/19819>. Acesso em: 13 ago. 2013.

RIBEIRO, M. Perspectivas da escola inclusiva: algumas reflexões. In: RIBEIRO, M.; BAUMEL, R. (Org.). Educação especial: do querer ao fazer. São Paulo: Avercamp, 2003. p. 4151.

RIVIÈRE, Á. O autismo e os transtornos globais do desenvolvimento. In: COLL, C.; MARCHESI, A.; PALACIOS, J. (Org.). Desenvolvimento psicológico e educação. 2. ed. Porto Alegre: Artmed, 2004. v. 3, p. 234-254.

ROSIN-PINOLA, A. R.; DEL PRETTE, Z. A. Inclusão escolar, formação de professores e a assessoria baseada em habilidades sociais educativas. Revista Brasileira de Educação Especial, Marília, v. 20, n. 3, p. 341-356, jul./set. 2014. Cross ${ }^{\text {Ref. }}$

SANINI, C.; SIFUENTES, M.; BOSA, C. A. Competência social e autismo: o papel do contexto da brincadeira com pares. Psicologia: Teoria e Pesquisa, Brasília, v. 29, n. 1, p. 99-105, jan./mar. 2013. Cross ${ }^{\text {Ref. }}$

SANT’ANA, I. M. Educação inclusiva: concepções de professores e diretores. Psicologia em Estudo, Maringá, v. 10, n. 2, p. 227-234, maio-ago. 2005. Cross ${ }^{\text {Ref. }}$ 
SEIDL-DE-MOURA, M. L. et al. Conhecimento sobre desenvolvimento infantil em mães primíparas de diferentes centros urbanos do Brasil. Estudos de Psicologia, Natal, v. 9, n. 3, p. 421-429, set./dez. 2004. Cross ${ }^{\text {Ref. }}$

SEKKEL, M. C.; ZANELATTO, R; BRANDÃO, S. B. Ambientes inclusivos na educação infantil: possibilidades e impedimentos. Psicologia em Estudo, Maringá, v. 15, n. 1, p. 117-126, jan.-mar. 2010. Cross ${ }^{\text {Ref. }}$

SERENO,D.Acompanhamentoterapêuticoeeducaçãoinclusiva. Psychê, São Paulo, v. 10, n. 18, p. 167-179, set. 2006. Disponível em: $\quad<$ http://pepsic.bvsalud.org/scielo.php?script=sci arttext\&pid=S1415-11382006000200016>. Acesso em: 20 jul. 2013.

SIFUENTES, M.; BOSA, C. A. Criando pré-escolares com autismo: características e desafios da coparentalidade. Psicologia em Estudo, Maringá, v. 15, n. 3, p. 477-485, set. 2010. Disponível em: <http:/www.scielo.br/pdf/pe/v15n3/ v15n3a05.pdf>. Acesso em: 24 ago. 2013.

SILVA, A. M.; MENDES, E. G. Psicologia e inclusão escolar: novas possibilidades de intervir preventivamente sobre problemas comportamentais. Revista Brasileira de Educação Especial, Marília, v. 18, n. 1, p. 53-70, jan./mar. 2012. Cross ${ }^{\text {Ref }}$

SILVA, M. A análise de necessidades na formação contínua de professores: um contributo para a integração e inclusão dos alunos com necessidades educativas especiais no ensino regular. In: RIBEIRO, M.; BAUMEL, R. (Org.). Educação especial: do querer ao fazer. São Paulo: Avercamp, 2003. p. 53-69.

SILVA, M.; MULICK, J. A. Diagnosticando o transtorno autista: aspectos fundamentais e considerações práticas. Psicologia: Ciência e Profissão, Brasília, v. 29, n. 1, p. 116131, 2009. Cross ${ }^{\text {Ref. }}$

TAMANAHA, A. C.; PERISSINOTO, J.; CHIARI, B. M Uma breve revisão histórica sobre a construção dos conceitos do autismo infantil e da síndrome de Asperger. Revista da Sociedade Brasileira de Fonoaudiologia, São Paulo, v. 13, n. 3, p. 296-299, 2008. Cross ${ }^{\text {Ref. }}$

TESSARO, N. S. et al. Inclusão escolar: visão de alunos sem necessidades educativas especiais. Psicologia Escolar e Educacional, Campinas, v. 9, n. 1, p. 105-115, jun. 2005. Cross ${ }^{\text {Ref. }}$

TONELLI, A. Autismo, teoria da mente e o papel da cegueira mental na compreensão de transtornos psiquiátricos. Psicologia: Reflexão e Crítica, Porto Alegre, v. 24, n. 1, p. 126-134, 2011. Cross ${ }^{\text {Ref. }}$

VYGOTSKY, L. S. Formação social da mente. 7. ed. São Paulo: Martins Fontes, 2007.

Recebido em: 11 de outubro de 2013

Aceito em: 1 de dezembro de 2015 